\title{
An Analysis and Scheduling Strategy for Water Resources
}

\author{
Yiwen $\mathrm{Wu}^{1}$ and Xiaofei $\mathrm{Wen}^{2, *}$ \\ ${ }^{1}$ College of Electrical and Information Engineering, Southwest Minzu University, Chengdu, 610225, China \\ ${ }^{2}$ College of Urban Planning and Architecture, Southwest Minzu University, Chengdu 610041, China \\ ${ }^{*}$ Corresponding author
}

\begin{abstract}
This article mainly Analyses the Strategy for Water Resources. First, we provide a model to discuss the ability of a region to provide clean water to meet the needs of its population. We pick Egypt to investigate why and how water is scarce in that region. We set the coefficient of the ability as $\alpha(t)$ is a dynamic factor, which is related to the economic factor. If $\alpha(t) \geq 0$, it indicates the region has the ability to provide clean water to meet the needs of its population. Referring to the data we get and Logistic model to get figures of Egypt. The result we acquired suggests that Egypt is a heavily water scarcity situation. $\varphi(t)$ Shows increasing trend with time and gradually get close to 0 . So we design the intervention plan. The one is artificial precipitation enhancement, the other is the desalination. From the overall analysis, it makes bad effects on Egypt's economic development.
\end{abstract}

\section{Keywords-water scarcity; logistic model; dynamic}

\section{INTRODUCTION}

Fresh water is a crucial resource for human being. It makes a deep influence on the development of the world. However, due to the humanity immoderate use and the serious pollution, the water resources supply and demand contradictory intensifies day by day. According to the United Nations, 1.6 billion people (one quarter of the world's population) experience water scarcity. We have known that water use has been growing at twice the rate of population over the last century. Water resources are sources of water that are useful or potentially useful. ${ }^{[1]}$

\section{THE MODEL FOR TASK 1}

In this part, we are supposed to provide a model to discuss the ability of a region to provide clean water to meet the needs of its population. Firstly, we investigate the supply quantity of the fresh water $[\mathrm{S}(\mathrm{t})]$. It includes the average annual precipitation (B), the water from the river basin in that region and the water resources transferred from other regions (C). However, the water from the river basin needs to clean. The ability to clean water is the economic factor. We set the coefficient of the ability as $\alpha(\mathrm{t})$ and the total water resource in that region as $\mathrm{W}$ is the physical factor. Secondly, we need to discuss the uses of the fresh water[U(t)]:

A. The residential purposes. The personal water consumption is multiplied by the population of the region $[P(t)]$ with the average water demand of people $(\beta)$.

B. Industrial. We set the use of fresh water for industrial over time as $\mathrm{I}(\mathrm{t})$
C. Agricultural. We set the use of fresh water for agricultural over time as $\mathrm{A}(\mathrm{t})$.

Finally, the model we constructed is followed:

$$
\begin{aligned}
& \mathrm{W} * \alpha(\mathrm{t})+\mathrm{B}+\mathrm{C}=\mathrm{S}(\mathrm{t}) \\
& \mathrm{P}(\mathrm{t}) * \beta+\mathrm{I}(\mathrm{t})+\mathrm{A}(\mathrm{t})=\mathrm{U}(\mathrm{t}) \\
& \mathrm{S}(\mathrm{t})-\mathrm{U}(\mathrm{t})=\varphi(\mathrm{t})
\end{aligned}
$$

$\alpha(t)$ is a dynamic factor, which is related to the economic factor. $\mathrm{W}$ is related to the physical factor, which is depended on the actual situation in the region we choose. We set the GDP of the region as $\mathrm{G}(\mathrm{t}), \alpha(\mathrm{t})=\mathrm{a} * \mathrm{G}(\mathrm{t})+\mathrm{b}$. In general, $\alpha(\mathrm{t})$ is growing in exponential form. What is more, both $S(t)$ and $\mathrm{U}(\mathrm{t})$ are parameters changing over time. $\varphi(\mathrm{t})$ represents the ability of a region to provide clean water to meet the needs of its population. And it is a dynamic parameter to represents the ability changes with time.

If $\alpha(t) \geq 0$, it indicates the region has the ability to provide clean water to meet the needs of its population. Else if, it indicates the region does not have the ability.

\section{THE MODEL FOR THE USES OF WATER}

Referring to the UN water scarcity map above, we pick Egypt to investigate why and how water is scarce in that region. Due to the environment around Egypt, the most important source of water is the Nile. It provides $5.5 * 1010 \mathrm{~m} 3$ of water every year. Taking the other water resources into account, Egypt has $5.55^{*} 1010 \mathrm{~m} 3$ of water resources per year.[2]According to the United Nations Human Development Report, the relationship between average water consumption of population and the situation of water scarcity in that region is shown in the following table:

TAB1E I. THE RELATIONSHIP BETWEEN AVERAGE WATER CONSUMPTION AND THE SITUATION OF WATER

\begin{tabular}{c|l}
\hline \hline $\begin{array}{l}\text { Average water consumption of } \\
\text { population/m3 }\end{array}$ & The situation of water scarcity \\
\hline $\mathrm{x} \geq 1700$ & Meet the normal needs \\
$1000 \leq \mathrm{x}<1700$ & Slightly water scarcity \\
$500 \leq \mathrm{x}<1000$ & Moderately water scarcity \\
$\mathrm{x}<500$ & Heavily water scarcity \\
\hline \hline
\end{tabular}

In this part, we build a formula to calculate $\mathrm{x}$ : 


$$
\mathbf{X}(\mathbf{t})=\frac{\mathbf{W} * \boldsymbol{\alpha}(\mathbf{t})+\mathbf{B}+\mathbf{C}}{\mathbf{P}(\mathbf{t})}
$$

The data of Egypt we get is followed: ${ }^{[3.4]}$

$$
\begin{aligned}
& \mathrm{W}=5.55 *\left(\mathrm{~m}^{3}\right) \\
& \mathrm{B}=1.4 *\left(\mathrm{~m}^{3}\right) \\
& \mathrm{C}=0\left(\mathrm{~m}^{3}\right) \\
& \mathrm{P}(2015)=84530442
\end{aligned}
$$

As we all know, the ability to clean water is related the economic factor. The change of $\alpha(\mathrm{t})$ is depended on the change of GDP in that region. From the data we get, [7] the following figure is obtained (as shown in the fig.1)
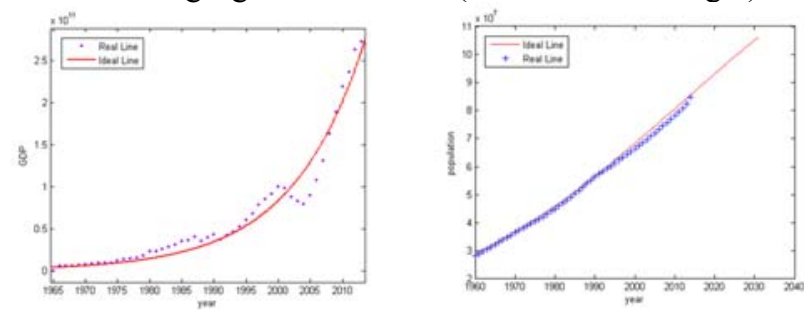

FIGURE I. THE GDP OF EGYPT FIGURE II. THE GROWING OF POPULATION IN EGYPT

We set the change of GDP as G(t), G(t) $=2.254 * 10-$ $66 \mathrm{e} 0.08815 \mathrm{t}$. And the change of the ability to clean water meet the following formula:

$$
(\mathbf{t})=\mathbf{a} * \mathbf{G}(\mathbf{t})+\mathbf{b}
$$

What is more, we have known that the water use has been growing at twice the rate of population over the last century. So we need to investigate the growing rate of population. Referring to the data we get [4] and Logistic model [5], we use MATLAB to get figures of Egypt. (as shown in the fig.2)

From the figure shown above, we acquire the growing rate of population is $\gamma=0.0298$. And the following formula is acquired:

$$
\mathrm{P}(\mathrm{t})=\frac{1.6881 * 10^{8}}{1+4.86 * \mathrm{e}^{-0.0298 *(\mathrm{t}-1960)}}
$$

We have known that the water use has been growing at twice the rate of population over the last century. So the growing rate of water use is $\delta(t)=2 * \gamma=0.0596$. And the growing rate of water use is the most important factor to calculate the coefficient of the ability to clean water.

From the data we collected, we draw out the proportion of water demand for agricultural change over time, and the figure is followed:

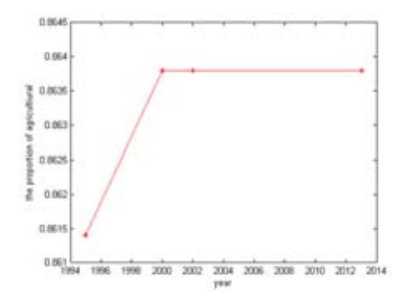

FIGURE III. DEMAND FOR AGRICULTURAL

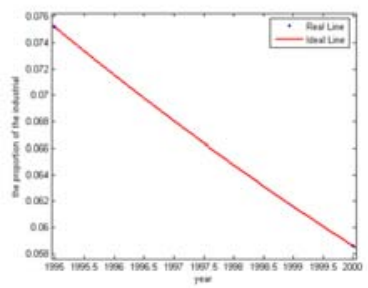

FIGURE IV. DEMAND FOR INDUSTRIAL

From the figure above, we obtain that the proportion of water demand for agricultural in $1995 \mathrm{a} 1995=0.8614$ and the proportion of agricultural in $2000 \mathrm{a} 2000=0.8638$. After 2000, $\mathrm{a}=0.8638$ is a constant.From the figure above, we obtain that the proportion of water demand for industrial for 1995 i1995 = 0.0752 and the proportion of industrial for $2000 \mathrm{i} 2000=$ $0.0586 . \mathrm{i}(\mathrm{t})=1.29 * 1042 * \mathrm{e}-0.0499 \mathrm{t}$.

According to the data we get from the figures above, we construct the model to infer its expression. From the data we get, a person's normal annual basic water consumption is 36.5 73m3. [6] We set the average water demand of people $\beta 0$ is a constant, $\beta 0=54.75 \mathrm{~m} 3$. The model is followed:

$\frac{\alpha(1995)}{\alpha(2000)}=\frac{\mathrm{G}(1995)}{\mathrm{G}(2000)}=\frac{601.6}{998.4}$

$\varepsilon(2000)=\frac{\frac{\mathrm{P}(2000) * \beta_{0}}{1-\mathrm{i}_{2}-\mathrm{a}_{2}}}{\mathrm{~W} * \alpha(2000)+\mathrm{B}}$

$\varepsilon(1995)=\frac{\frac{\mathrm{P}(1995) * \beta_{0}}{1-\mathbf{i}_{1}-\mathrm{a}_{1}}}{\mathrm{~W} * \alpha(1995)+\mathrm{B}}$

$\frac{\varepsilon(2000)}{\varepsilon(1995)}=(1+\delta)^{\Delta t}$

$\Delta \mathrm{t}=2000-1995=5$

$\mathrm{W}=5.55 * 10^{10}\left(\mathrm{~m}^{3}\right)$

$\mathrm{B}=1.4^{*} 10^{8}\left(\mathrm{~m}^{3}\right)$

$\mathrm{P}(2000)=66136590$

$\mathrm{P}(1995)=61168397$

$\beta_{0}=54.75$

Then we get $\alpha(1995)=0.0265, \alpha(2000)=0.0439$. The model we developed is followed:

$$
\begin{aligned}
& \mathrm{G}(\mathrm{t})=2.254 * \\
& \alpha(\mathrm{t})=\mathrm{a} * \mathrm{G}(\mathrm{t})+\mathrm{b} .
\end{aligned}
$$


So, $\alpha(\mathrm{t})=1.33 * 10-78 \mathrm{e} 0.08815 \mathrm{t}-0.0051$. And the figure of $\alpha(\mathrm{t})$ is followed:

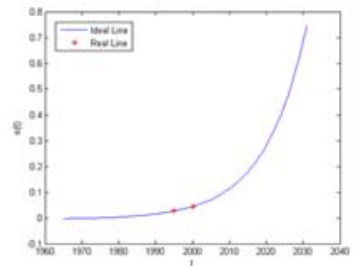

FIGURE V. THE COEFFICIENT OF THE ABILITY TO GET FRESH WATER

The demand of the fresh water includes the use for industrial, the use for agricultural, and the use for residential purposes. From the figure of 4, we get the proportion of the $\mathrm{A}(2015)$ to the $\mathrm{U}(2015)$ is $86.38 \%$. From the figure of 5 , we get the proportion of the $\mathrm{I}(2015)$ to the $\mathrm{U}(2015)$ is $2.77 \%$. So, the proportion of residential purposes is $10.85 \%$. In that way, it is easily to obtain:

$$
\begin{aligned}
& \mathrm{U}(2015)=\frac{\mathrm{P}(2015) * \beta_{0}}{1-2.77 \%-86.38 \%}=4.265 * 1010 \mathrm{~m}^{3} \\
& \mathrm{~S}(2015)=\mathrm{W} * \alpha(2015)+\mathrm{B}+\mathrm{C}=1.00523 * 1010 \\
& \alpha(2015)=0.1786 \\
& \mathrm{I}(2015)=\mathrm{S}(2015) * 2.77 \%=2.78449 * 10^{8} \mathrm{~m}^{3} \\
& \mathrm{~A}(2015)=\mathrm{S}(2015) * 86.38 \%=8.68318 * 109 \mathrm{~m}^{3} \\
& \mathrm{P}(2015)=84530442 \\
& \mathrm{y}(2015)=\frac{\mathrm{S}(2015)-\mathrm{I}(2015)-\mathrm{A}(2015)}{\mathrm{P}(2015)}=12.903 \mathrm{~m}^{3} \\
& \mathrm{x}(2015)=\frac{\mathrm{W} * \alpha(2015)+\mathrm{B}+\mathrm{C}}{\mathrm{P}(2015)}
\end{aligned}
$$

We get the average water consumption of people $x(2015)=118.92 \mathrm{~m} 3$ and the average water consumption of residential purposes $\mathrm{y}(2015)=12.903 \mathrm{~m} 3$. However, the average water demand of residential purposes for one is 36.5 $\mathrm{m} 3$ at least. The result we acquired suggests that Egypt is a heavily water scarcity situation.

\section{THE CHANGING TENDENCY OF WATER SITUATION}

Referring to the model we constructed above, we acquire the demand of the fresh water $U(t)=\frac{P(t) * \beta_{0}}{\left(1-a_{t}-i_{t}\right)}$ and the supply quantity of the fresh waterS(t) $=\mathrm{W} * \alpha(\mathrm{t})+\mathrm{B}+\mathrm{C}$.

According to the model for task $1, \varphi(\mathrm{t})=\mathrm{S}(\mathrm{t})-\mathrm{U}(\mathrm{t})$. $\varphi(t)$ reflects the ability of a region to provide clean water to meet the needs of its population. Using MATLAB, we draw out the figure:

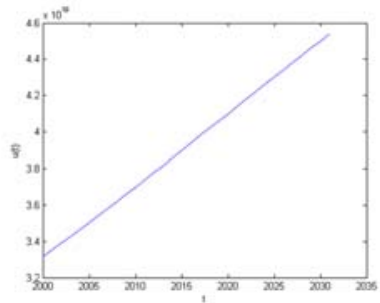

FIGURE VI. THE DEMAND OF THE FRESH WATER

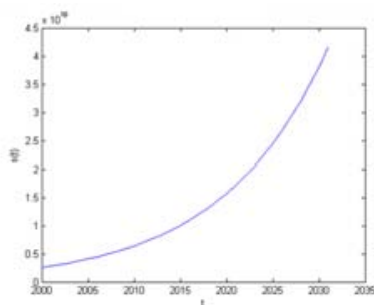

FIGURE VII. THE SUPPLY QUANTITY OF THE FRESH WATER

The demand of fresh water for people in Egypt from 2000 to 2031 is rising because of the rising of the population. The supply quantity of the fresh water in Egypt from 2000 to 2031 is rising because of the rising of the economic factors

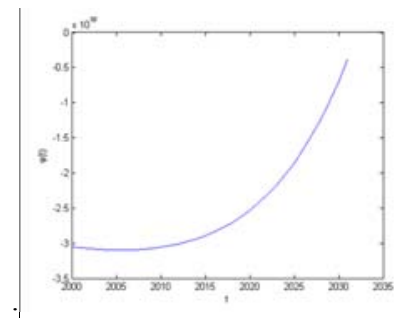

FIGURE VIII. THE ABILITY OF A REGION TO PROVIDE CLEAN WATER TO MEET THE NEEDS OF ITS POPULATION

From the overall analysis, $\varphi(t)$ shows increasing trend with time and gradually get close to 0 . However, the demand of the fresh water has been greater than the supply quantity of fresh water in the next 15 years. Such a long period of water shortage makes it hard to meet the normal needs of the fresh water for people, the demand of fresh water for industrial and the demand of fresh water for agricultural. What is more, it makes bad effects on Egypt's economic development.

\section{THE INTERVENTION PLAN}

Considering about the average water consumption of population:

$$
\mathrm{x}(\mathrm{t})=\frac{\mathrm{W} * \alpha(\mathrm{t})+\mathrm{B}+\mathrm{C}}{\mathrm{P}(\mathrm{t})}
$$

we design the intervention plan from the following two aspects.

- Artificial precipitation enhancement

From the data we collected, through artificial precipitation enhancement, the precipitation will increase by $25 \%$. [8] And the formulas are followed: 


$$
\begin{aligned}
& \mathrm{B}=(1+25 \%) * \mathrm{~B} \\
& \mathrm{~B}=1.4 * 108 \mathrm{~m} 3
\end{aligned}
$$

Through the method of artificial precipitation enhancement, the annual precipitation in Egypt reaches B $=2.1 * 108 \mathrm{~m} 3$.

- The desalination

Because of the implementation of the sea water desalination, Saudi Arabia has $3.066^{*} 1013 \mathrm{~m} 3$ water augmentation every year. The GDP of Saudi Arabia for 2015 is $6.82583^{*} 109$, and the GDP of Egypt for 2015 is 2.75868*1011. Considering about the GDP of Saudi Arabia and Egypt, so Egypt has $1.23913 * 109 \mathrm{~m} 3$ water augmentation every year.

- The result of the intervention plan

From the model we discussed above, we developed the model for $\mathrm{x}(\mathrm{t})$ is followed:

$$
\begin{aligned}
& \alpha(\mathrm{t})=1.32984393 * 10^{-78} * \mathrm{e}^{0.08815 * \mathrm{t}}-0.0051 \\
& \mathrm{P}(\mathrm{t})=\frac{1.6881 * 10^{8}}{1+4.86433369 * \mathrm{e}^{-0.0298 *(\mathrm{t}-1960)}} \\
& \mathrm{x}(\mathrm{t})=\frac{\left(5.55 \mathrm{e}+010 * \alpha(\mathrm{t})+2.1 * 10^{8}+1.23913 * 10^{9}\right)}{\mathrm{P}(\mathrm{t})}
\end{aligned}
$$

Referring to the model we developed, we draw out the figure of $\mathrm{x}(\mathrm{t})$ as follows:

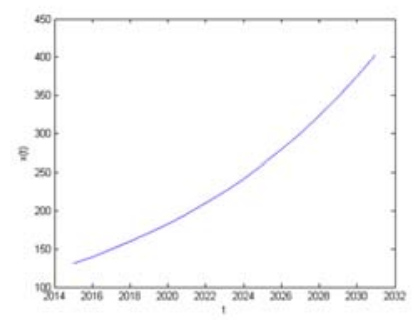

FIGURE IX. THE AVERAGE WATER CONSUMPTION OF POPULATION OVER TIME AFTER IMPLEMENTING THE INTERVENTION PLAN

From the figure shown above, we know that the average water consumption of population is less than $500 \mathrm{~m} 3 \mathrm{in}$ the next 15 years after implementing the intervention plan, which indicates that our chosen region is still susceptible to water scarcity. And the intervention plan does not bring a great impact for water scarcity in Egypt.

\section{ACKNOWLEDGMENT}

This work is financially supported by the Fundamental Research Funds for Central University, Southwest Minzu University (2017NZYQN02).

\section{REFERENCES}

[1] The current situation of global water resources [J] Natural Resource Economics of China, 2015, (4): 42.

[2] Egypt's water resources and future policy[J] World Agriculture, 2006 (4): 42-46

[3] Climate Change Knowledge Portal (CCKP)

http://sdwebx.worldbank.org/climateportal/index.cf-m?page $=$ country_historical_climate $\&$ ThisRegion=Africa $\&$ ThisCCode $=$ EGY
[4] The population of Egypt. http://www.phb123.com/city/renkou/2586.html

[5] Wang Yong, Logistic population model to solve the problem, Beijing, Journal of Harbin University of Commerce (NATURAL SCIENCE EDITION), 05, 2006.

[6] The dilemma of the Nile. http://www.eedu.org.cn/Article/eehotspot/freshwater/201201/69457.htm 1

[7] World-Publicdata. https://www.google.nl/publicdata/explore?ds $=\mathrm{d} 5$ bncppjof $8 \mathrm{f} 9$ \& met $\mathrm{y}=$ ny_gdp mktp_cd\&idim $=$ country $\% 3$ AEGY\%3AISR $\% 3$ ALEY $\& h l=z h \_C N \& d l=z$ h_CN

[8]

Precipitation. http://big5.xinhuanet.com/gate/big5/news.xinhuanet.com/weather/200902/17/content_10831376.htm. 